\title{
FROM DANTE'S UNIVERSE TO CONTEMPORARY COSMOLOGY
}

\author{
Nota del s.c. MARCO BERSANELLI (*)
}

(Adunanza del 6 ottobre 2016)

SunTO. - Una lettura della Divina Commedia con gli occhi di uno scienziato moderno rivela che Dante ha riservato grande attenzione alla descrizione di una vasta gamma di fenomeni naturali, in particolare quelli legati all'astronomia, all'ottica e alla geometria. Un esempio notevole riguarda la struttura generale del cosmo così come emerge dagli ultimi canti del Paradiso nei quali, come fu notato per la prima volta dal matematico elvetico Andreas Speiser nel 1925, viene suggerita una struttura non-Euclidea dello spazio. In tal modo Dante concepisce un universo in cui le sfere astronomiche e quelle angeliche sono disposte simmetricamente e mosse dal Punto divino, il vero centro dell'universo, posto agli antipodi della Terra. Tale struttura presenta una sorprendente somiglianza con il modello cosmologico di Einstein del 1917, caratterizzato da curvatura positiva (3-sfera) e reso statico dalla famosa introduzione di un valore ad-hoc della costante cosmologica. Tale modello, così come altre soluzioni basate su valori marcatamente non-nulli della costante di curvatura, risultano oggi esclusi dalle osservazioni astrofisiche. In questo contributo si descrive l'intuizione geometrica di Dante e se ne discute la plausibilità nel contesto della sua poetica e del suo orizzonte culturale. Si descrive inoltre la coincidenza topologica della "3-sfera dantesca" con la curvatura dello spazio-tempo nel contesto del modello cosmologico standard, oggi fortemente confermato da osservazioni di alta precisione quali quelle ottenute dal satellite Planck dell'ESA.

$$
* * *
$$

ABSTRACT. - A reading of the Divina Commedia with the eyes of a modern scientist reveals that Dante devoted great attention to the description of a wide variety of natural phenomena, particularly those involving astronomy, optics and geometry. A remarkable case is the structure of the cosmos emerging from the Paradiso, which foreshadows a non-Euclidean geometrical structure with remarkable similarities to Einstein's 1917 static cosmological solution. Such model, however, as well as other solutions with positive spatial curvature, are ruled out by current astrophysical observations. Here I dis-

(*) Dipartimento di Fisica, Università degli Studi di Milano, Italia.

E-mail: marco.bersanelli@mi.infn.it 
cuss Dante's geometric intuition and show its close analogy with the shape of the observable cosmic space-time in the standard CDM expanding model, fully supported by present-day cosmological data.

\section{DANTE'S VISION OF THE NATURAL WORLD}

A modern scientist running into Dante's Divina Commedia will discover several passages where the description of a wide variety of natural phenomena related to astronomy, optics, geometry, physics, mathematics, geology, ethology, are treated with remarkable attention. ${ }^{1}$ For example, light and its diverse manifestations provide a central element in the scenography of the Commedia. Dante frequently uses light as a metaphor of divine realities and of moral virtues, but in so doing he also occasionally describes its physical properties exhibiting the skill of a careful naturalistic observer. In Purg. XV (16-21), for example, when Dante encounters the angel of mercy, appearing to him as a glare of reflected divine light, he goes as far as giving a rigorous description of the law of reflection expressed in verses:

Come quando da l'acqua o da lo specchio

salta lo raggio a l'opposita parte,

salendo su per lo modo parecchio

a quel che scende, e tanto si diparte

dal cader de la pietra in igual tratta,

si come mostra esperienza e arte;

This passage shows that Dante's understanding of optics ("perspectiva") was not based just on commonsense, but it was rooted in some level of methodical study, likely based on the works of Alhazen and Witelo (Nardi 1990, Gilson 1999). It also shows that he felt no discomfort with including detailed accounts of natural phenomena in his poetry, rather, he used them to introduce additional richness in his narration. In Purg. XXV, 91-93, we find a beautiful description of the rainbow that goes as follows:

1 The significance of the scientific dimension in Dante's writing has been the subject of a vast literature, see e.g. Capasso (1967), Gizzi (1974), Di Scipio \& Scaglione (1983), D’Amore (1994), Stabile (1997), Gilson (1999), Ledda (2001), Peterson (2002), Ricci (2005), Buti \& Bertagni (2008). 
E come l'aere, quand'è ben pïorno, per l'altrui raggio che ' $n$ sé si reflette, di diversi color diventa addorno.

Here, in the same terzina, Dante gives a poetic rendering of the rainbow (l'aere... di diversi color diventa addorno), but he also provides a synthetic account of the physical mechanism responsible for its appearance, i.e., the reflection of solar light (l'altrui raggio) in the droplets of moist in the atmosphere (l'aere... ben piorno). ${ }^{2}$

Another notable example is the discussion of the nature of the dark spots on the Moon in Paradiso II. Here we find a combination of empirical observation, logical reasoning, and even the suggestion of an experimental approach. Indeed, in making her final case to rule out the hypothesis that the lunar dark spots are due to sunlight reflected from deeper regions in the Moon surface, Beatrice proposes the following optics experiment (Par. II, 97-105):

Tre specchi prenderai; e $i$ due rimovi da te d'un modo, e l'altro, più rimosso, tr'ambo li primi li occhi tuoi ritrovi.

Rivolto ad essi, fa che dopo il dosso

ti stea un lume che i tre specchi accenda

e torni a te da tutti ripercosso.

Three mirrors should be placed at different distances, as to represent a model of the irregular surface of the Moon, supposed to be everywhere reflective, with the central mirror further away than the two lateral ones. The light from a candle, which mimics the Sun rays, is reflected back by the three mirrors into the eyes of the observer. The conclusion is that:

Ben che nel quanto tanto non si stenda la vista più lontana, li vedrai come convien ch'igualmente risplenda.

2 Several medieval scholars studied in detail the physics of the rainbow, including Robert Grosseteste and Albert the Great. In 1310 a contemporary Dante's, the German Dominican Theodoric of Freiberg, in his work De iride et radialibus impressionibus correctly described the shape and colours of the rainbow as a combination of reflection and refraction of sunlight in the water droplets in the atmosphere (Grant 1974). 
Although the solid angles - as we would say in the language of modern physics - of the three images of the flame are different, the one coming from the mirror placed further away being smaller (ben che nel quanto tanto non si stenda), their surface brightness is the same (they shine with the same intensity: igualmente risplenda). Since the light from the Sun covers completely the exposed surface of the Moon, this would result in equal luminosity in every part of the Moon disc, which falsifies ${ }^{3}$ the hypothesis. This is a remarkably accurate, non-trivial physical observation. The fact that the surface brightness (not the flux density) is independent of distance ${ }^{4}$ is a straightforward concept for a modern physicist, but surely not obvious for a medieval poet. In fact, a number of non-physicist commentators of the Commedia have seriously misunderstood Dante's "three-mirror experiment", labelling his conclusions as obviously wrong or absurd, or just insisting on the purely allegorical nature of the situation being described. ${ }^{5}$

Dante's deep interest in the physical world, as well as his audacious imagination, were rooted in a cultural view where everything was believed to have a role and a meaning. In the medieval mentality, each creature was thought to be created for a purpose and was in relation with the whole. From the rainbow to the whole universe, every natural reality was considered a sign of the Creator, and for this reason worthy of attention and consideration. As Beatrice states in Par I (103-108):

[...] Le cose tutte quante

hanno ordine tra loro, e questo è forma

che l'universo a Dio fa simigliante.

3 Interestingly, here Beatrice uses precisely the word "falsified" (e s'elli avvien ch'io l'altro cassi, / falsificato fia lo tuo parere. Par. II, 83-84), a term that is retained in modern philosophy of science.

4 This is true assuming that absorption from the medium (air in this case) is negligible, a fully justified condition in this case.

5 E.g., Parodi (1922), Corsano (1975), Boyde (1993). Interestingly, in discussing this topic Patrick Boyde reproduces a XV Century miniature representing Dante's three-mirror experiment in which the flame images look exactly the same. This testifies that, not surprisingly, not only modern commentators but also ancient ones have been deceived by the optical setup described by Dante. 
In Dante's poetry there is a distinction, but not a dichotomy, between natural phenomena and their metaphysical dimension. Physics and aesthetics live together. Clearly Dante's mindset was quite different from the one, far more specialized and fragmented, typical of our modern era. Now days, no scientist would think of including in an academic paper any aesthetic appreciation of the system under study, and probably no poet would dear giving a rigorous account of a physical law in her/his artwork.

The fascinating interplay between physical and metaphysical, between geometry and virtue, reaches an apex in Dante's narration in the last Canti of Paradiso, where an unprecedented cosmic picture is suggested.

\section{DANTE'S UNIVERSE}

The iconography of Dante's cosmos, as normally depicted in textbooks, appears rather cumbersome. The central Earth is surrounded by the spheres of the seven planets, by the Stellatum with the fixed stars, by the Primum Mobile, and ultimately by the Empyrean; then, separated from the astronomical universe, we normally see an additional structure composed by a set of nine concentric circles; and then the Candida Rosa is often drawn in some intermediate region. It is hard to believe that Dante, with his deep appreciation for symmetry and unity, at the apex of his cosmic journey presents us with such disconnected image of the universe. Indeed, this awkward cosmic map is the consequence of an apparent internal contradiction present within the text of the Divina Commedia.

In Dante's times the traditional cosmography was a simplified Aristotelian-Ptolemaic universe, a system that was enthusiastically adopted by medieval scholars after the rediscovery of Greek authors. Importantly, however, the medieval Christian culture added a tenth sky beyond the Primum Mobile, the Empyrean, inhabited by the angels, the blessed ones, and by God himself. Often the Empyrean was further divided into nine concentric circles representing the nine "angelic choirs", each corresponding to an astronomical sphere. The remarkable XIV century fresco by Piero di Puccio, in Piazza dei Miracoli, Pisa, shows the nine Empyrean heavens surrounding the Primum Mobile and the nested astronomical orbs around the central Earth. 
In several places Dante's description seems to follow closely such traditional world picture. For example, when Dante and Beatrice approach the Primum Mobile, the Empyrean is depicted as the outmost sphere full of light and love surrounding the entire universe (Par. XXVII, 112-114):

Luce e amor d'un cerchio lui comprende, si come questo li altri; e quel precinto Colui che 'l cinge solamente intende

Here, Colui che l'cigne is God himself, imagined as the ultimate outer rim of the Empyrean. This is coherent with Par. XIV, 30, where God is described as non circunscritto e tutto circunscrive. ${ }^{6}$

However, in Par. XXVIII, 13-39, when Dante and Beatrice look out into the Empyrean from the Primum Mobile, they experience a surprising view. They see a bright point of pure light - so bright that Dante is nearly dazzled - surrounded by nine concentric fiery circles, widely extending over the whole visible space (Par. XXVIII, 31-34). The speed and the luminosity of the nine circles increase in proportion to their proximity to the center. The bright central point represents God himself, as a foreshadow of what will become Dante's ultimate divine vision at the end of the poem. As Beatrice explains, the nine circles are the angelic orders, symmetric to the astronomical spheres, forming a mirror image of the physical universe ${ }^{7}$ (Fig. 1). However, contrary to the physical spheres, their rotation speed increases towards the centre. Puzzled by this velocity asymmetry Dante asks Beatrice, who clarifies that the correspondence between the Empyrean and astronomical spheres is to be found in their degree of virtute, not in their physical size (Par. XXVIII, 46-78).

In summary, in some passages Dante's Empyrean is the traditional all-encompassing tenth sphere around the Primum Mobile, God being its ultimate limit; in others, it is pictured as a separated structure, literally as «another universe» (l'altro universo, XXVIII, 71), a reverse image of the astronomical world (Lewis 2006), with God as a vivid

6 See also: Purg. XI, 2; Par. II, 112-114; Conv. IV, IX 3.

7 The number 9 completes the recursive structure encountered in the nine circles of Hell and in the nine levels of Purgatory. 
infinitesimal Point at its centre. How is this possible? How can God be represented as the outmost sphere embracing the cosmos and, at the same time, as a single point of light? In Par. XXX, speaking of the divine Point, Dante exacerbates the paradox by stating in one single verse that they are both simultaneously (Par. XXX, 10-12):

\section{...il trïunfo che lude sempre dintorno al punto che mi vinse, parendo inchiuso da quel ch'elli 'nchiude.}

There is a further puzzle. The place on the Primum Mobile from where Dante and Beatrice contemplate the Empyrean scene is a generic, unimportant location. This is explicitly remarked by Dante, as he states that the Primum Mobile is so uniform that he can't tell where on the sphere Beatrice lead him (Par. XXVII, 100-102). But if the Empyrean is "another universe", somehow adjacent to the physical one, Dante and Beatrice must find themselves at the gate to the Empyrean, a very special viewpoint where they can contemplate the angelic universe that they will soon enter. How can such heavenly door be indicated as an insignificant place?

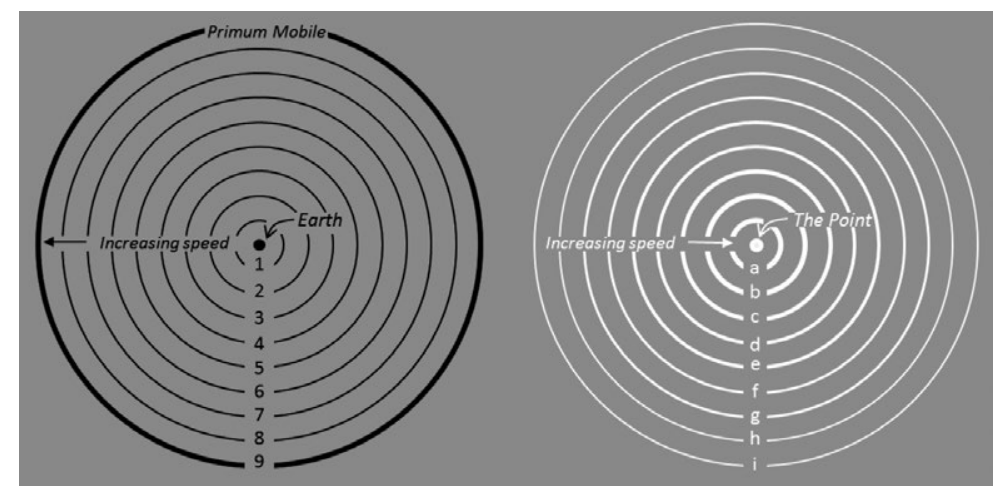

Fig. 1 - Schematic of Dante's cosmos. Left: the arrangement of the astronomical spheres around the Earth. From 1 to 9 the circles represent the spheres of the Moon, Mercury, Venus, the Sun, Mars, Jupiter, Saturn, the fixed stars, and the Primum Mobile. Right: the Empyrean circles with the nine angelic orders. From $a$ to $i$ the circles represent: Seraphim, Cherubim, Thrones, Dominions, Virtues, Powers, Principalities, Archangels, Angels (Par. XXVIII, 97-126). Their luminosity and rotation speed increase towards the centre. The correspondence between the physical and angelic spheres is according to their virtue, which is in inverse order with their size, i.e.: $a \rightarrow 9$, $b \rightarrow 8, \ldots i \rightarrow 1$. 
When Dante and Beatrice leave the Primum Mobile to move beyond, the vision of the Point and of the angelic circles fades away (Par. XXX, 1-15). New and deeper levels of vision of the Empyrean, and of God himself, will become accessible to Dante as he will be more and more deeply immersed in the heavenly realm (Par. XXX, 1-15). This is coherent with what Dante experienced throughout his journey in the Paradiso: as he ascends, his sight increasingly gains the capability to sustain and grasp the ineffable realities he encounters (e.g., Par. XXX, 76-81, XXXIII, 109-114). Indeed, the geometrical structure described in Canto XXVIII is just a limited vision of the Empyrean, the partial image of it that can be glimpsed from within the Primum Mobile - which after all is still part of the mondo sensibile. While such geometric structure does not capture the whole nature of the Empyrean, its peculiar arrangement and the apparent inconsistency it implies require some kind of explanation.

\section{A SPHERICAL SPACE}

Is there a way to reconcile Dante's cosmic contradictions? An implicit, apparently obvious, assumption in all of the above discussion is that the underlying space where the scheme of Fig. 1 is drawn is a flat sheet of paper: an Euclidean two-dimensional space. However, if we draw the same scheme on a 2-d spherical space, like the surface of a globe (see Fig. 2), all the apparent contradictions are readily resolved. This is best seen by using our modern geometric language. A spherical surface of radius $R$ centred at the origin is described by the familiar equation $x_{0}^{2}+x_{1}^{2}+x_{2}^{2}=R^{2}$. The sections $x_{2}=k$, with $|k| \leq R$, are circles parallel to the $\left(x_{0}, x_{1}\right)$ plane with radius $\left(R^{2}-k^{2}\right)^{1 / 2}$. An observer moving in any direction from the point $(0,0, R)$ (the Earth in Dante's scheme, north pole in Fig. 2), will encounter increasingly larger circles (the astronomical orbs), each containing all the previous (and smaller) ones. Moving beyond the equator $\left(x_{2}=0\right)$, the observer will now cross increasingly smaller circles, i.e., the angelic choirs. Now, however, as the observer moves on, the new sections crossed will include larger sections. Eventually the crossed circles converge around a single point at $(0,0,-$ R) («The Point» in Fig. 1).

Now the physical universe and the Empyrean are symmetric to 
each other, like the two hemispheres of Fig. 2. The Empyrean surrounds everywhere the Primum Mobile and, at the same time, it is ultimately converging on a single point, the antipodal of the Earth. The velocities of all circles (astronomical and angelic) are now naturally ordered in proportion to their proximity to the divine Point (a proximity that defines their virtute), and their sizes are reversed in the two hemispheres. Also, it is now clear why the vision of the angelic circles does not depend on the specific position of the observer on the Primum Mobile: the scheme is completely symmetric around the equator.
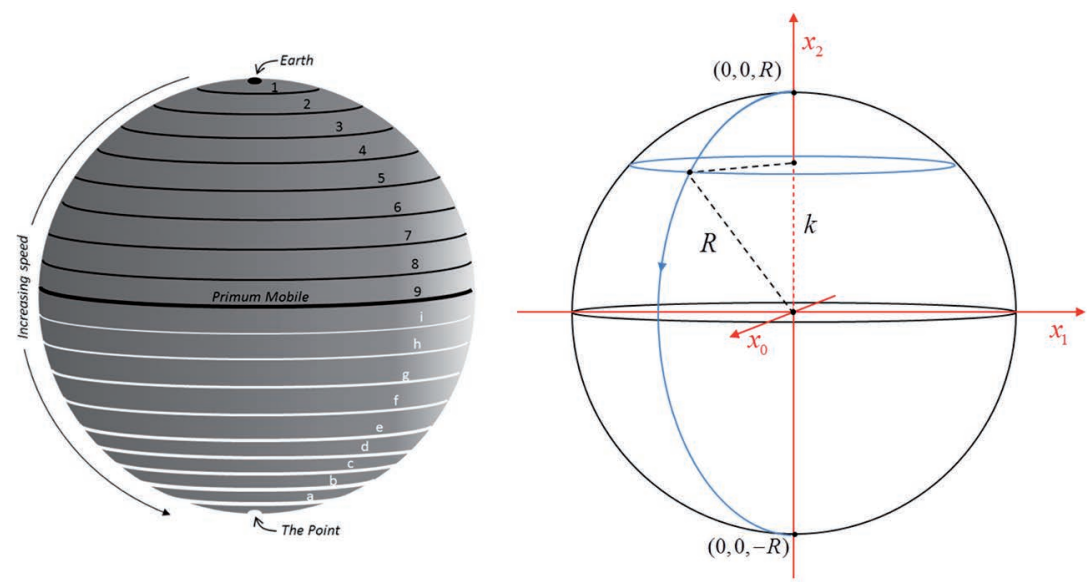

Fig. 2 - Dante's spherical universe. Left: The two arrangements of Fig. 1 (the physical and angelic circles of Dante's cosmos), are here drawn on a 2-d spherical space. The numbers and letters correspond to those of Fig. 1. Note that the rotation velocities in this case increase regularly from "Earth" to "The Point". Right: coordinate system for the sphere (see text).

Of course Figs. 1-2 represent two-dimensional maps of the true 3$\mathrm{d}$ space, since each circle represents a sphere. In the case of Fig. 2, the extra dimension implies that the underlying space is a 3 -sphere, or hypersphere, i.e. the analogue of a $2-\mathrm{d}$ spherical surface in one more dimension. The analytical expression for a 3 -sphere centred in the origin and with radius $R$ is simply:

$$
\sum_{j=0}^{3} x_{j}^{2}=x_{0}^{2}+x_{1}^{2}+x_{2}^{2}+x_{3}^{2}=R^{2}
$$


We cannot visualize a 3 -sphere, but we can visualize its sections with constant values of $x_{3}=k$ with $|k| \leq R$. Similarly to previous case, these sections are a set of concentric spheres (not circles) of radius $\left(R^{2}-k^{2}\right)^{1 / 2}$. Their radius, as seen by an observer moving outwards in a generic direction, increases up to $x_{3}=0$ and then diminishes until the spheres converge around a point at $x_{3}=-R$. In Dante's image, that antipodal point includes all the spheres of the universe, astronomical and angelic. In this view Dante's enigmatic description of the divine Point makes perfect sense: parendo inchiuso da quel ch'elli 'nchiude (XXX, 10-12). God is the true centre of the cosmos: Da quel punto depende il cielo e tutta la natura (Par. XXXIII, 41-42). The Earth is the anti-centre of the universe, l'infima lacuna de l'universo (Par. XXXIII, 22-23), with Lucifer buried at its centre, da tutti li pesi del mondo costretto (Inf. XXIX, 57). All the apparent contradictions are resolved, the poetry can be better understood and more deeply enjoyed.

The first modern-time suggestion of this reading of Dante's cosmic geometry, as far as I know, was made in 1925 by Swiss mathematician Andreas Speiser (Speiser 1925). Interestingly, Speiser was working on non-Euclidean geometry, an expertise that enabled him to readily recognize the nature of Dante's intuition. A number of authors have further discussed this interpretation (Callahan 1976, Peterson 1979 , Osserman 1995, Patapievici 2004, Egginton 1999; Bersanelli 2012, Rovelli 2014). Of course Dante did not have the mathematical language we have today, and his notion of a curved space must have been purely qualitative, far from the rigorous description given above. In fact, it is straightforward for us to describe a non-Euclidean space, while it surely required a stunning imagination for Dante to think something like that without the aid of mathematics. Is it realistic that he could have conceived such counterintuitive, yet coherent, geometrical structure?

A few elements should be considered. First, at Dante's time the geometrical imagination was less rigidly anchored to the Newtonian paradigm than it is today. As a matter of fact, Dante was more familiar with spherical astronomy than with plane Euclidean geometry (Egginton 1999). Furthermore, at that time the notion of a spherical Earth, while widely accepted, was sufficiently paradoxical that conceiving the same situation in one more dimension may have been not such a great leap of imagination as it is for us today. Interestingly, Dante's 
mentor Brunetto Latini, in the first book of his encyclopedic work $L i$ Tresor, to explain the spherical shape of the Earth does not describe it as a sphere seen from outside. Instead, he tells the story of two horsemen travelling in opposite directions, who end up finding themselves in front of one another at the opposite side of the globe (Rovelli 2014). This must have been an astonishing thought at the time. Brunetto sees spatial curvature from within space, not from outside. Indeed, this is the most straightforward way for us to grasp curvature in 3-d space as well. Just as, on the 2-d spherical Earth, a horseman going straight in any direction will find himself at the antipodes, in a 3 -spherical space an astronaut flying straight on a spaceship will reach the antipodal point of the universe. And if the horseman and the astronaut will keep going long enough, they will both come back to their starting points.

\section{THE $21^{\text {ST }}$ CENTURY VIEW}

Since Dante's times, we have learnt a great deal about the nature of our physical universe. Today we routinely observe large numbers of galaxies - each containing $\sim 10^{11}$ stars - distributed rather uniformly in deep space. We have also realised that our universe is expanding and we can measure accurately the time to the beginning of cosmic expansion: about 13.8 billion years (Planck Collaboration 2016). In spite of light's great speed, $c \sim 10^{8} \mathrm{~m} / \mathrm{s}$, cosmic distances are so great that light takes a long time to cross them. The photons from the furthest galaxies travelled up to 12-13 billion years before reaching us, and therefore we see those galaxies as belonging to a relatively young universe, only 1 or 2 billion years old. However, because of expansion, that young universe was also much smaller than it is today. We may suspect that those spherical layers of the universe that we see far away, which surround us at very large distances, are actually smaller than the huge space they contain. This is indeed the case. A paradox that immediately reminds us of Dante's spherical geometry: smaller spheres that include larger ones.

To look at the picture in more detail we need to use again mathematical language. In relativistic cosmology we describe space-time in an expanding isotropic and homogeneous universe through the FriedmanLemaitre-Robertson-Walker (FLRW) metric: 
$d s^{2}=-c^{2} d t^{2}+R(t)^{2}\left[d \chi^{2}+S_{k}^{2}(\chi) d \psi^{2}\right]$

where $d t$ is the infinitesimal time interval, $d \chi$ is the comoving coordinate separation, ${ }^{8}$ and $d \psi^{2}=d \theta^{2}+\sin ^{2} \theta d \phi^{2}$ is the angular distance on the sphere. The function $R(t)$ is the expansion term, measured in units of length. The function $S_{k}(\chi)$ takes the values $\sin \chi, \chi, \sinh \chi$ for closed $(k=+1)$, flat $(k=0)$, and open $(k=-1)$ models, respectively. The proper distance $D(t)$ between the origin and a given point in space-time is defined on a surface of constant time, $d t=0$. If we then consider radial distances only, so that $d \psi=0$, equation [2] reduces to $d s=R(t) d \chi$, and by integration we have $D(t)=R(t) \chi$. Differentiating this relation yields:

$\dot{D}=\dot{R} \chi+R \dot{\chi}=v_{\text {rec }}+v_{\text {pec }}$

where over-dot represents a time derivative. The velocity in terms of proper distance is thus the combination of two terms: a recession term, $v_{\text {rec }}$, representing the effect cosmic expansion; and a peculiar velocity, $v_{\text {pec }}$, representing the motion relative to the comoving coordinates system. The first term can be rewritten as the familiar Hubble law:

$v_{\text {rec }}(t)=\dot{R}(t) \chi=H(t) D(t)$

where $H=\dot{R} / R$ is the Hubble parameter, and its value at present time, $H\left(t_{0}\right)=H_{0}$, is defined as the Hubble constant.

The second term is useful to understand the motion of a photon in the expanding space. Light rays move along null geodesics in the FLRW metric, i.e. along paths corresponding to $d s=0$. Considering again radial propagation $(d \psi=0)$, from [2] we obtain $c d t=R(t) d \chi$. This can be rewritten as:

$\dot{\chi}_{\text {light }}=\frac{c}{R(t)}$,

which shows that the velocity of a photon through comoving coordinates is not constant, but depends on the expansion factor $R(t)$. Therefore, to calculate the comoving distance of a galaxy that emitted light at time $t_{\mathrm{em}}$, we need to integrate the changing comoving speed of

8 Comoving coordinates are defined such that they remain fixed for object that follow the expansion flow, i.e., with zero peculiar motion. (In this work we follow the notation of Peacock 1999). 
light (eq. [5]) from that time to the present. This yields the equation for our "past light cone" in the expanding universe:

$\chi_{\text {light cone }}\left(t_{\mathrm{em}}\right)=c \int_{t_{\mathrm{em}}}^{t_{0}} \frac{d t^{\prime}}{R\left(t^{\prime}\right)}$

The past light cone represents the set of all the events in the universe that are visible to us today. Light rays travel following the light cone and bring to us images of different galaxies at different stages of their evolution. Integration of equation [6] shows that, for any realistic cosmological model, ${ }^{9}$ our past light cone has the shape schematically shown in Fig. 3.

Assuming negligible peculiar motion, our world line (i.e., the path of our location in space-time) is the central vertical line of Fig. 3. World lines of distant galaxies, such as G1, G2 and G3, diverge from our world line as a consequence of cosmic expansion..$^{10}$ We see those galaxies at the time when their world lines intersect our past light cone. The galaxies G1, G2 and G3 are at increasing distances into our past light cone, therefore we observe them to recede from us at increasing rates.

For galaxies relatively nearby (say, up to G1), our light cone is nearly linear (Fig. 3). In this region the proper distance is simply proportional to the time it took for light to reach us, as it would be in a static universe. But as we move further away - e.g., between G1 and G2 the shape of our light cone is curved towards the origin. This means that, as we look back into the past, the proper distance of the objects we see grows more and more slowly. At G2, the proper distance reaches a maximum. This is the so-called "maximum emission distance", i.e., the region of the universe where the galaxies we observe today were furthest away from us when they emitted the light we see. ${ }^{11}$ Beyond that

9 Here we assume the standard CDM cosmological model, i.e., a flat expanding space and with matter and vacuum energy densities contributing, respectively, for $\sim 30 \%$ and $\sim 70 \%$ of the total energy density.

10 In Fig. 3 the world lines are straight lines. A more rigorous calculation would show a slight bending with positive curvature, due to time variation of the Hubble term. However, our simplification has no impact on our discussion.

11 In the standard model this happens at a cosmic time of $\sim 5$ billion years, corresponding to a redshift of $\sim 1.5$. 
point, something remarkable happens: as we look at earlier epochs we see galaxies that were closer and closer to us when they emitted the light we see today. In other words, we see those galaxies as belonging to spheres, centred on our observing point, smaller than the spheres they encompass. Note that beyond G2 the slope of the light cone becomes negative, i.e., photons emitted at those early times were receding from us. This is because at that time the expansion rate exceeded the speed of light, ${ }^{12}\left(v_{\text {rec }}-c\right)>0$. This is in no contradiction with special relativity: the expansion rate can be superluminal since it is a velocity that describes the dynamics of space itself, not the movement of an object through space.

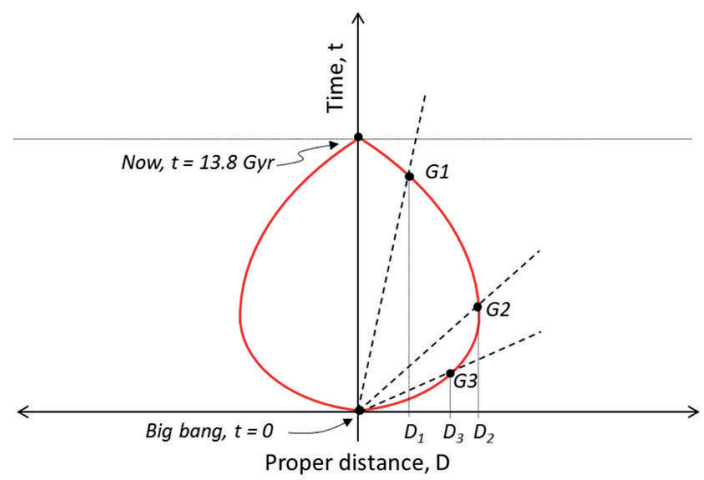

Fig. 3 - The shape of our past light cone (red line). Time (vertical axis) spans from the big bang $(t=0)$ to the present epoch (13.8 billion years, or Gyr). The slope of the light cone at any time is the velocity of light relative to us at that time: this is not constant, but it is equal to $v_{\text {rec }}-c$. A rotation around the vertical axis of the red curve is a 2-d surface topologically equivalent to a sphere. In analogy with Fig. 2, any constant-time section in Fig. 3 (circles parallel to the vertical axis, not shown), represents a sphere. We see the galaxies G1, G2 and G3 as belonging to spheres centred on us and nested into one another. As we look beyond G2, we observe smaller spheres encompassing larger ones (G3 is beyond $G 2$, but $D_{3}<D_{2}$ ). In scale of this drawing, the last scattering surface is much smaller than the black point indicated as "big bang" at $t=0$.

We may ask: how far can we actually see into our past light cone? How deep can we see towards the initial point in space-time, the "big

12 The limit beyond which, at any given time, the recession of galaxies exceeds the speed of light is known as the "Hubble sphere". 
bang"? The deepest view we have of the early universe is the cosmic microwave background (CMB), a sea of photons released when the universe was about $3.8 \times 10^{5}$ years old, only $0.003 \%$ of its present age. The $\mathrm{CMB}$ photons traveled rather undisturbed in their 13.8 billion year journey, so they bring to us a remarkably faithful view of the so-called "last scattering surface" (LSS), the sphere of space-time surrounding us where the CMB photons last interacted with matter. The LSS surrounds us as an ultimate cosmic photosphere seen from the inside. Beyond that surface, the universe was opaque to light. Today we have a detailed image of the LSS thanks to accurate full-sky observations of the CMB, such as those recently obtained by the ESA Planck satellite shown in Fig. 4 (Planck Collaboration 2016; see also Bersanelli 2013).

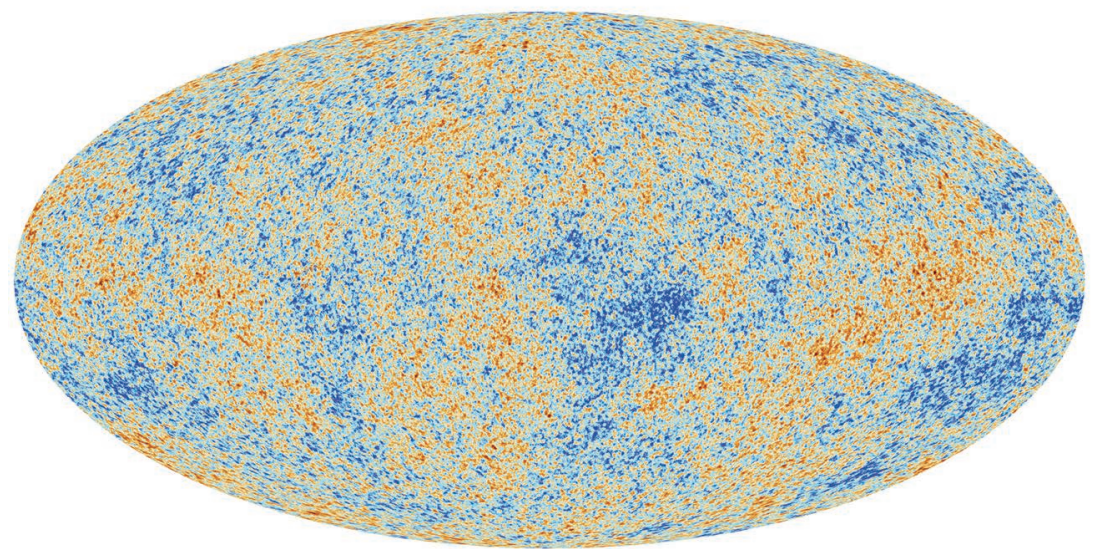

Fig. 4 - Full-sky image of the last scattering surface from the latest data from the Planck satellite (Planck Collaboration 2015). The intensity of the CMB (color scale in brightness temperature, $\pm 300 \mu \mathrm{K}$ ) traces small fluctuations in the density and velocity of the primordial hot plasma, whose statistics encode a wealth of information on the structure, composition, evolution and geometry of the universe (credit: ESA and Planck Collaboration).

How large is the last scattering surface? The answer requires care. Calculated at the present cosmic epoch, the material that last interacted with the $\mathrm{CMB}$ is now at a distance of $\sim 42$ billion light-yeas (about 3 times what we would expect in a static universe). However, this is not what we see: we observe the LSS at the time it released the photons, i.e., when its radius was much smaller than today. Calculation shows that the radius of the LSS as we actually see it, is only 38 million light-years, 
much smaller than the space it contains. Paradoxically, the ultimate visible sphere in the sky surrounding us in all directions, is dramatically smaller than the space occupied by all the galaxies we observe in between (see Fig. 5).

The shape of our past light cone is symmetric around the time axis, and it points in any direction towards the initial big bang. This means that, when we look up in the sky in any direction, we are actually looking towards a single point in space-time, the origin of the universe.

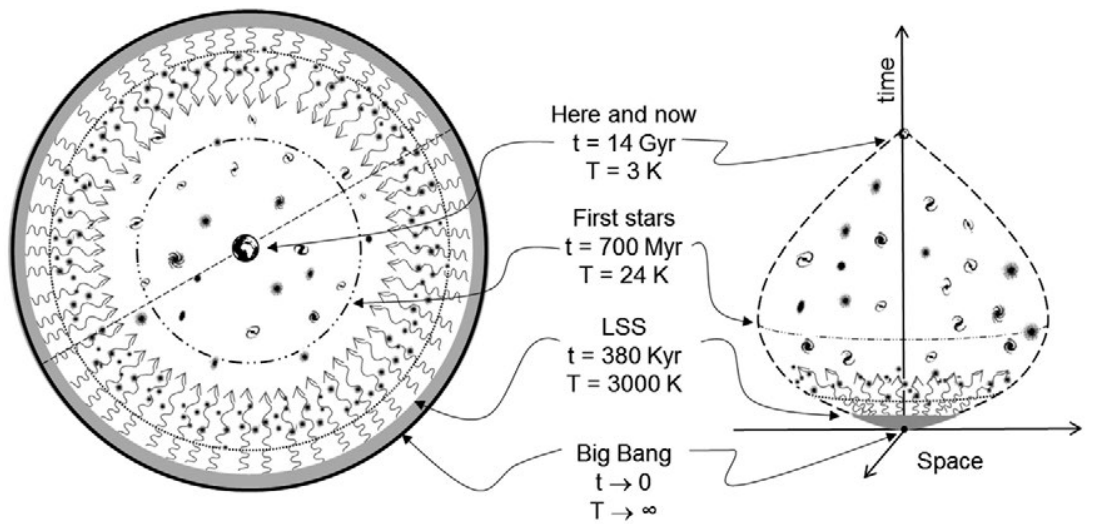

Fig. 5-Schematic showing some of the key phases in the evolution of the universe: the big bang, the last scattering surface, the formation of the first stars, and the present time. Left: events are shown in concentric spheres, as they appear to our observation; right: the same events are depicted on our past light cone.

\section{CONCLUSIONS}

This picture has eloquent similarities with Dante's cosmos. Indeed, the topology of our past light cone is identical to that of the hypersphere imagined by Dante in his Paradiso. Clearly, we should note an important difference: in the modern vision we deal with a curvature of space-time, while in Dante's case the curvature was spatial only.

Most previous discussions of the subject (e.g., Speiser 1925, Callahan 1976, Peterson 1979, Lachieze-Rey \& Luminet 1995, Buonanno \& Quercellini 2009, Rovelli 2014) highlighted the similarity 
between Dante's universe and a positively curved Riemann space (i.e., a model with $\mathrm{k}=+1$ in eq. [2]), such as the famous static model by Einstein (1917) with a fine-tuned cosmological constant. Such closed models, however, are highly disfavoured by present-day observations. Here, following Osserman (1995), we have discussed Dante's geometrical vision in connection with the shape of the observable space-time in a generic expanding cosmology, the simplest case of which being a flat expanding universe. In recent years, precise cosmological observations strongly indicate a spatially flat universe with matter density $\Omega_{M}=\Omega_{B}+$ $\Omega_{C D M} \approx 0.3$ (including baryonic matter, $\Omega_{B}$, and cold dark matter, $\Omega_{C D M}$ ) and vacuum energy density $\Omega_{\Lambda} \approx 0.7$, the so-called standard $\Lambda$ CDM cosmological model. In particular, the recent full-sky observations of the $\mathrm{CMB}$ by the Planck satellite provide measurements of the basic parameters of the CDM model with unprecedented accuracy, at $~ 1 \%$ level or less (Planck Collaboration 2015). Surprisingly, therefore, it turns out that the visionary intuition of the medieval poet Dante Alighieri has a strong analogy with the best general description of cosmic space-time as revealed by $21^{\text {st }}$ century science.

While remarkable, these analogies should not be misunderstood. Dante had no physical or quantitative argument to support his ideas, and his cosmic vision was based entirely on imagination. It would be a mistake to treat his cosmological insight as a scientific theory in a modern sense. Nonetheless, it is noteworthy that his open-minded thinking, his relentless search for a beautiful, meaningful and coherent description of the world lead him to foreshadow concepts that modern science would confirm and develop on scientific basis seven centuries later.

Perhaps the situation is not dissimilar from what happened with some of the great ancient Greek thinkers. Consider, for example, Democritus' intuition of the atomic structure of matter; or Anaxagoras' insight that heavenly bodies are made out of earthly materials: in these cases too, modern science has shown the basic correctness of these ideas, in spite of the fact that their ancient authors could not support them with empirical evidence. Similarly the hypersphere architecture of Dante's universe, originated by his genius rooted in the medieval culture, represents a fascinating original thought in cosmology and should be regarded as a wonderful hidden jewel in the history of scientific ideas. 


\section{BIBLIOGRAPHY}

Bersanelli, M., 2012. Light in the Beginning, in «Light from light. Scientists and theologians in dialogue», Ed. by Gerald O'Collins, S.J. and Mary Ann Meyers, Cambridge: Wm. B. Eerdmans Publishing Co., pp. 80-101.

Bersanelli, M., 2013. Missione spaziale Planck: Verso l'alba del tempo, Istituto Lombardo, Rend. Scienze, 147, 183-209.

Boyde, P., 1993. L'esegesi di Dante e la Scienza, in «Dante e la Scienza», Ed. by Patrick Boyde \& Vittorio Russo, Longo Editore, pp. 14-16.

Buonanno, R. and Quercellini, C., The equations of medieval cosmology, New Astronomy 14 (2009), pp. 347-348.

Buti, G., and Bertagni, R., (2008). Commento astronomico della Divina Commedia, Edizioni Remo Sandron, Firenze (2008).

Callahan, J.J., 1976. The curvature of space in a finite universe, Scientific American, vol. 235, pag. 90-100.

Capasso, I., 1967. L'astronomia nella Divina Commedia, Domus Galileana.

Corsano, A., 1975. Dante e la scienza del suo tempo, Bollettino di Storia della Filosofia, Università degli Studi di Lecce, vol. 3, pp. 69-80.

D’Amore, B., 1994. La matematica nella Divina Commedia, Alma Mater Studiorum, Università di Bologna, anno VII, n. 1.

Davis, T.M., and Lineweaver, C.H, 2004. Expanding Confusion: Common Misconceptions of Cosmological Horizons and the Superluminal Expansion of the Universe; Publications of the Astronomical Society of Australia; Vol. 21, Issue 1, pp. 97-109.

Di Scipio, G.C., and Scaglione, A., 1983. The Divine Comedy and the Encyclopedia of Arts and Sciences, Acta of the International Dante Symposium, 13-16 Nov. 1983, Hunter College, New York.

Egginton, W., 1999. On Dante, Hyperspheres, and the Curvature of the Medieval Cosmos, Journal of the History of Ideas, Volume 60, n. 2, pp. 195-216.

Einstein, A. 1917. Kosmologische Betrachtungen zur allgemeinen Relativitätstheorie. Sitz. König. Preuss. Akad. 142-152. Or 'Cosmological considerations in the general theory of relativity' in (Lorentz et al. 1952): 175-188. CPAE 6 (Doc. 43).

Gilson, S., 1999. Light Reflection, Mirror Metaphors, and Optical Framing in Dante's Comedy: Precedents and Transformations, Neophilologus, n. 83, pp. 241-52.

Gizzi, C., 1974. L'astronomia nel poema sacro, Lofredo.

Grant, E., 1974. A Source Book in Medieval Science. Harvard University Press.

Lachieze-Rey, M., Luminet, J.P., Cosmic Topology, Phys.Rept. 254 (1995) 135-214.

Ledda, G., 2001. Poesia, scienza e critica dantesca: due libri recenti sull'ottica e l'astronomia in Dante, L'Alighieri A. 42, n. 18, pp. 99-113.

Lewis, C.S., 2006. The discarded image, Cambridge University Press, p.116.

Nardi, B., 1990. Il Canto XV del Purgatorio, Lecturae ed altri studi danteschi.

Osserman, R., 1995. A Mathematical Exploration of the Cosmos, Anchor Books, 1995

Parodi, E.G., 1922. Il Canto II del Paradiso, letto da Ernesto Giacomo Parodi nella sala di Dante in Orsanmichele, Sansoni.

Patapievici, H.-R., 2004. Gli occhi di Beatrice, Mondadori. 
Peacock, J.A., 1999. Cosmological Physics, Cambridge University Press.

Peterson, M.A., 1979. Dante and the 3-sphere, American Journal of Physics, 12, 1031.

Peterson, M.A., 2002. Galileo's discovery of the scaling laws, American Journal of Physics, 70, 575.

Planck Collaboration, 2016. Planck 2015 results. I. Overview of products and results; Astronomy and Astrophysics, 594, A1.

Ricci, L., 2005. Dante's insight into Galilean invariance, Nature vol. 434, p. 717.

Rovelli, C., 2014. La realtà non è come ci appare, Cortina, pp. 83-95.

Speiser, A., 1925. Das Raumende und das Jenseits, in «Klassiche Stücke der Mathematik», Orell Füssli.

Stabile, G., 1997. Bartolomeo da Parma e l'astronomia di Dante, Seventh Centenary of the Teaching of Astronomy in Bologna, 1297-1997, Proceedings of the meeting held in Bologna at the Accademia delle Scienze, pp. 99-122. 
